\title{
Política industrial como política de inovação: notas sobre hiato tecnológico, políticas, recursos e atividades inovativas no Brasil*
}

Tatiana Massaroli Melo**

José Ricardo Fucidji***

Mario Luiz Possas****

Recebido: 31/07/2014 Versão Revisada (entregue): 17/02/2015 Aprovado: 27/02/2015

RESUMO

Este artigo discute uma dimensão central da política industrial em economias modernas e globalizadas: a política de inovação. A partir da abordagem evolucionista, é abordada a relação entre hiato tecnológico e competitividade. A seguir, a proposição central do texto é formulada, mostrando a relação entre política industrial, acumulação de competências tecnológicas e competitividade internacional. Esta orientação da política industrial, porém, deve ir além do fomento e da oferta de recursos (financeiros e humanos) para as atividades inovativas e ocupar-se dos determinantes do baixo esforço inovativo das empresas brasileiras.

PalaVras-CHAVE | Política Industrial; Inovação; Capacitações; Competitividade

CÓdigos JEL | O25; O31; O32

\footnotetext{
* Os autores agradecem o apoio financeiro recebido do CNPq, o trabalho do corpo editorial e da secretaria executiva da RBI e os comentários de três pareceristas anônimos.

** Universidade Estadual Paulista “Júlio de Mesquita Filho” (Unesp), Araraquara (SP), Brasil. E-mail: tmassaroli@fclar.unesp.br

*** Universidade Estadual Paulista “Júlio de Mesquita Filho" (Unesp), Araraquara (SP), Brasil. E-mail: jrfucidji@fclar.unesp.br

**** Universidade Federal do Rio de Janeiro (UFRJ), Rio de Janeiro (RJ), Brasil. E-mail: mpossas@unisys.com.br
} 


\title{
Industrial Policy as Innovation Policy: notes on technological gap, policies, resources and innovative activities in Brazil
}

\begin{abstract}
This paper deals with a central dimension of industrial policies in modern, globalized, economies, namely innovation policy. From an evolutionary approach it points out the relationship between technology gaps and competitiveness. Next, our core proposition is claimed, by showing the link among industrial policies, technological capabilities accumulation and international competitiveness. The proposed orientation of industrial policy should, however, go beyond support and (financial and human) resource supply measures, and to inquire the determinants of low innovation efforts by the Brazilian firms.
\end{abstract}

KeYwords | Industrial Policy; Innovation; Capabilities; Competitiveness

JEL-Codes | O25; O31; O32 


\section{Introdução}

Um dos temas mais controversos da literatura econômica, nas duas últimas décadas, tem sido o da existência, critérios e operacionalidade da política industrial. Stiglitz, Lin e Monga (2013) têm o mérito de mostrar como os altos e baixos dos fundamentos teóricos da política industrial estão relacionados com concepçôes mais ou menos otimistas em relação à operação ótima dos mercados no sistema econômico. Além disso (uma concepção que também vamos adotar), os autores mostram que as políticas industriais estão sempre presentes, quer sejam reconhecidas explicitamente, ou não - e, mais que isso, elas têm um caráter inescapavelmente diferenciado em seus impactos setoriais. $\mathrm{O}$ argumento aqui proposto, portanto, não visa defender a pertinência de políticas industriais, nem advogar em favor de políticas verticais de apoio à indústria: seria ocioso, posto que tais argumentos abundam na literatura. Nosso objetivo é enfatizar um papel específico da política industrial - entendida como o conjunto de medidas cuja finalidade é promover o desenvolvimento da estrutura industrial: o de promoção de atividades inovativas.

Duas considerações cautelares se fazem necessárias. Primeira, esta definição de política industrial difere da visão mais ampla (por exemplo, novamente, em STIGLITZ; LIN; MONGA, 2013) de que todas as atividades que levam ao aprendizado e ao acúmulo de conhecimento podem ser consideradas sob o âmbito da política industrial, mesmo que não estejam na indústria de transformação. Não negamos o papel difusor de novas tecnologias que o setor industrial tem sobre o restante da economia, mas, por isso mesmo, retemos a centralidade do setor industrial e concentramos nele a nossa atenção. Segunda, apontar que o objetivo da política industrial é promover a geração e difusão de inovações (que sejam capazes de impulsionar ganhos persistentes na produtividade e na qualidade dos bens e serviços) não é propriamente uma contribuição original; há inclusive, na literatura, argumentos em favor de uma nova política industrial ${ }^{1}$ que enfatiza exatamente este aspecto (RODRIK, 2006; AGHION et al., 2012; O'SULLIVAN et al., 2013; DEVLIN; MOGUILLANSKY, 2013; OECD, 2013), além deste já ser um ponto há muito destacado no pensamento evolucionista (entre outros, BELL; PAVITT,

1 Outros elementos que caracterizam a nova política industrial (termo utilizado para designar o restabelecimento ou o "rejuvenescimento" da política industrial na discussão acadêmica e governamental) incluem, além da preocupação com o aprendizado tecnológico: maior ênfase em mão de obra qualificada em engenharia; uso mais eficiente de recursos (manufatura sustentável); acesso a financiamento; coordenação dos diversos sistemas de produção; interação entre o setor público e o setor privado; e, reconhecendo a dispersão global de atividades produtivas, entendimento do papel dos sistemas de produção nacionais nas cadeias de valor globais (O'SULLIVAN et al., 2013, p. 434). 
1993; POSSAS, 1996; ERBER, 2001; CIMOLI; DOSI; STIGLITZ, 2009; DOSI; GRAZZI; MOSCHELLA, 2014).

Nossa contribuição consiste em colocar essa discussão no contexto brasileiro de busca de competitividade internacional da indústria. Assim, propomos que o principal determinante da competitividade é a busca por inovações, que gera capacitação tecnológica e que esta deve ser a principal orientação da política industrial. Competitividade é aqui entendida como a capacidade de concorrer, traduzida em participação crescente das exportações nos mercados internacionais de produtos mais dinâmicos (ver, no mesmo sentido, POSSAS, 1999, cap. 6).

$\mathrm{O}$ texto está organizado em cinco seções, além desta introdução. Discute-se que o incremento da competitividade depende da busca por inovaçóes, reduzindo o hiato tecnológico (seção 2). Logo, o papel central da política industrial deve ser o de uma política de inovação (seção 3). Esta política, porém, não deve se limitar à oferta de recursos para a inovação (seção 4), mas também gerar pressões no ambiente seletivo que induzam as empresas a efetivamente realizarem atividades inovativas. Segue-se um esforço preliminar e exploratório de mensuração da distância tecnológica do Brasil em relação a alguns países europeus, com base em dados recentes de surveys nacionais de inovação (seção 5). Por fim, apresentamos as principais conclusōes (seção 6).

\section{Competitividade e hiato tecnológico}

A relação entre desempenho tecnológico, desempenho exportador e crescimento econômico tem sido amplamente analisada pela literatura econômica (ANTIMIANI; CONSTANTINI, 2013; FAGERBERG; SRHOLEC, 2008; FAGERBERG et al., 2007; FAGERBERG, 1994; DOSI; SOETE, 1988; NELSON; WINTER, 1982; POSNER, 1961). As análises mais interessantes frequentemente são aquelas encontradas fora da abordagem tradicional (mainstream), por sua melhor caracterização tanto do fenômeno do progresso técnico quanto das instituições e agentes envolvidos. Por exemplo, na abordagem evolucionista, é habitual considerar a existência de feedbacks entre capacitações tecnológicas desenvolvidas nacionalmente e crescimento econômico (MAGGI, 1993).

Os trabalhos sobre hiato tecnológico mais frequentes na literatura analisam a relação entre taxas diferenciais de crescimento do PIB per capita, nos vários países, e suas taxas de progresso técnico. A tecnologia é analisada como fator incorporado à estrutura das organizações, sendo a transferência entre elas difícil e custosa. A 
mudança tecnológica, portanto, é vista como o resultado conjunto de inovação e atividades de aprendizado dentro das organizaçóes, especialmente das firmas. Fatores específicos a cada país dão às tecnologias, e ao processo de mudança tecnológica, um caráter nacional ("tecnologia nacional"). Nesse sentido, a empresa assume o papel de principal indutor do progresso técnico, uma vez que as capacitaçôes produtivas e tecnológicas localizam-se em seu âmbito (FAGERBERG, 1994).

Para Fagerberg e Verspagen (2013), embora os países em desenvolvimento apresentem maiores possibilidades de crescimento, como é o caso de China e Índia, em relação às economias desenvolvidas, a transformação deste crescimento potencial em crescimento real passa pelo importante desafio de construir capacitaçôes para explorar as oportunidades para o catching up econômico e tecnológico, traduzido em ganhos de competitividade. A relação entre competitividade e hiato tecnológico pode ser esboçada do seguinte modo: se a inovação está relacionada à modificação nos padrões de produção existentes (cf. SCHUMPETER, 1942), determinando vantagens diferenciais para o inovador, a manutenção ou expansão da competitividade (a capacidade de competir) depende não apenas de competências produtivas, mas, principalmente, de competências para gerar e administrar a mudança técnica (BELL; PAVITT, 1995, p. 76-77; LALL, 1992) em ritmo igual ou superior ao dos concorrentes. O hiato tecnológico interessa, nesse contexto, diretamente como medida de distância entre o nível tecnológico de um país vis-à-vis seus concorrentes, mais do que como explicação para os níveis diferenciais de renda per capita, como é usual na literatura.

Considerando o argumento de Dosi e Soete (1983), o que explica grande parte da liderança tecnológica dos países desenvolvidos em relação aos em desenvolvimento é a existência de assimetrias tecnológicas, as quais são explicadas pelo desenvolvimento da estrutura produtiva de cada país e pela capacidade dessa estrutura de introduzir bens, serviços, processos, entre outros, que os outros países não são capazes de produzir, independentemente do custo. Analisando os países desenvolvidos, Bell e Pavitt (1995) argumentam que a transferência de tecnologia e know-how produtivo não é suficiente para conquistar e manter uma boa posição competitiva. É preciso investimento em capacitação tecnológica, para produzir, sempre que necessário, mudanças na produção, a fim de manter ou aumentar a competitividade. Ao encerrar seu texto, os autores pontuam que "o volume e a eficácia destes investimentos, que são principalmente específicos às firmas, dependem da competência tecnológica, da direção, da qualificação da força de trabalho, dos incentivos que as firmas têm para investir em acumulação tecnológica e da eficácia 
das instituições de apoio especializadas" (BELL; PAVITT, 1995, p. 101). Para os autores, tais instituições são os laboratórios de $\mathrm{P} \& \mathrm{D}$, mas poderíamos estender a noção para todo o sistema nacional de inovação.

Contrariando as teorias tradicionais que preveem ganhos da especialização das economias no comércio internacional, evidências têm apontado que as assimetrias tecnológicas entre países, resultado da especialização, afetam negativamente o desempenho competitivo dos latecomers no comércio mundial (DOSI; SOETE, 1983; DOSI; PAVITT; SOETE, 1990; AMENDOLA et al., 1993). Elas sugerem que as capacitações tecnológicas relativas de cada economia, em cada setor, são um poderoso determinante da parcela de exportação daquele país, naquele setor, no mercado mundial. Dessa forma, a parcela das exportaçôes indica a competitividade de cada país e esta depende da capacitação tecnológica. De acordo com Tigre (2002, p. 249), a competitividade internacional está, em grande medida, ligada ao crescimento de novas indústrias, à busca de economias de escala dinâmicas, às inovaçôes de processo e ao fomento de atividades científicas e tecnológicas.

No caso brasileiro, este autor aponta que um dos desafios ao aumento do desempenho exportador é a maior articulação entre as políticas comercial e tecnológica. Enquanto a primeira dá pouca atenção à variável tecnológica, priorizando o crédito às exportaçôes (BNDES), a política tecnológica por vezes subestima a importância das exportaçôes para estimular o desempenho tecnológico da indústria brasileira (TIGRE, 2002, p. 277). A partir de 2003, no entanto, com a criação do programa Brasil Exportador e maior atuação da Apex na promoção de diversificação da pauta de exportaçóes e conquista de novos mercados, as políticas comercial e tecnológica tornaram-se mais integradas. A Apex, em parceria com o MDIC, o BNDES e a Finep, desenvolveu o programa Plataformas de Exportação, cujo objetivo é incentivar a construção de plantas industriais com foco nas exportaçóes, e o Programa de Adequação Tecnológica para Exportação, com enfoque na resolução de problemas tecnológicos das micro e pequenas empresas.

\section{Política industrial como política de inovação}

A noção de política industrial adotada neste texto enfatiza as especificidades e a diversidade da estrutura industrial como um elemento-chave para o desenvolvimento de instrumentos de política que possuam como objetivo fomentar a competitividade das empresas locais no mercado internacional. Nesse sentido, a política industrial deve dar as condições necessárias para a consolidação de um sistema nacional de 
inovação, destacando a importância do setor privado nacional como principal agente responsável pela dinamização tecnológica da estrutura produtiva e consequente inserção internacional em mercados tecnologicamente mais avançados. Esta forma de abordagem do tema está alinhada aos desenvolvimentos teóricos mais recentes (GADELHA, 2001; GUERRIERO, 2011; REINER; STARITZ, 2013; REINERT, 2007; CIMOLI et al., 2009), os quais reforçam o papel da política de inovação como instrumento poderoso da política industrial.

Dessa forma, política industrial é entendida não apenas como a internalização de setores ausentes da matriz industrial e o incentivo a setores já instalados (embora também possa sê-lo), mas principalmente como a mobilização e implementação de mecanismos específicos para o desenvolvimento tecnológico, com o objetivo de reduzir as divergências competitivas e de padrōes de desenvolvimento entre os países desenvolvidos e em desenvolvimento. Se considerarmos o conceito de desenvolvimento segundo a tradição evolucionista de inspiração schumpeteriana, o progresso técnico é o motor do desenvolvimento capitalista. A política industrial, assim entendida, deve atender aos objetivos de fomentar o progresso técnico, diferentemente da teoria econômica tradicional, cujo enfoque está nas falhas de mercado e externalidades (GUERRIERO, 2011, p. 77). Cimoli et al. (2009, p. 4) argumentam que uma das consequências das últimas décadas de globalização foi o aprofundamento das divergências tecnológicas, das taxas de crescimento e dos níveis de renda per capita entre os países desenvolvidos e em desenvolvimento. Evidências encontradas pelos autores sugerem que a principal causa deste hiato é a dificuldade crescente dos países em desenvolvimento para absorver conhecimentos de tecnologias de produção e design de produtos desenvolvidos pelos países que estão na fronteira tecnológica.

Para que economias em desenvolvimento, como a brasileira, sejam tecnologicamente dinâmicas, é necessário que possuam um setor industrial nacional em expansão e capaz de absorver as tecnologias dos países que atuam na fronteira tecnológica. $\mathrm{O}$ argumento de que os países em desenvolvimento estão inseridos num contexto de globalizaçáo e que suas implicações em termos de liberalização e perda de autonomia nacional possam fornecer as condições necessárias para o catch up tecnológico mostra-se equivocado e não é amparado pela literatura sobre política industrial (CHANG, 2004; CIMOLI et al., 2009; STIGLITZ et al., 2013; WARWICK, 2013), que aponta que todos os países atualmente considerados desenvolvidos utilizaram políticas deliberadas para acumular capacitações tecnológicas, de forma a alcançar as tecnologias de produção e designs dos produtos da fronteira. Isso é o que Reinert (2007) chama de emulação, a realização de esforços deliberados 
de imitação de produtos e processos baseados nos novos paradigmas tecnológicos, independentemente das vantagens comparativas do país. Logo, para obter o catch up e com isso promover desenvolvimento econômico, ao menos no atual contexto em que a competitividade internacional é intensiva em inovaçôes, é necessário acompanhar a fronteira tecnológica.

Uma abordagem recente sobre a atuação da política industrial na promoção do desenvolvimento econômico leva em conta o papel do setor privado. Segundo tal análise (REINER; STARITZ, 2013, p. 53; REINERT, 2007), se o país possui um setor privado tecnologicamente dinâmico e capaz de interagir com a política pública, será mais fácil realizar investimentos e inovações, condições necessárias para o desenvolvimento econômico. Os autores argumentam que um dos desafios a serem enfrentados pelos formuladores de política industrial nos países em desenvolvimento é promover o desenvolvimento de competências tecnológicas no setor privado, estimulando as empresas líderes a perseguirem esforços de modernização da produção local. Nesse contexto, o processo de catch up tecnológico de economias em desenvolvimento, além de depender de atividades de alto valor adicionado desenvolvidas por produtores locais, está atrelado também à capacidade destas atividades de se integrarem à produção global, criando oportunidades de aprendizado, acumulação e spillovers de conhecimento capazes de aproximar estas economias da fronteira tecnológica.

O foco da política industrial em grande parte dos países desenvolvidos e em desenvolvimento mais bem-sucedidos tem sido as atividades industriais de alto conteúdo tecnológico e, portanto, com potencial para conquistar fatias do mercado internacional. Alguns exemplos de políticas orientadas para o fortalecimento de posições competitivas de empresas locais pela adequação da estrutura produtiva nacional aos padrōes de produção da fronteira tecnológica são encontrados em Warwick (2013, p. 8-9). Nos anos recentes, França, Holanda, Japão e Coreia do Sul têm orientado suas políticas para aumentar a competitividade industrial, utilizando para tanto a política tecnológica como instrumento de política industrial. Estas experiências mostram que muitos países têm reconhecido na política tecnológica um instrumento poderoso de promoção da competitividade e inserção internacional.

A consideração da política de inovação como o elemento precípuo de orientação da política industrial deve-se ao reconhecimento de que a empresa é o agente fundamental da dinâmica econômica em economias capitalistas e, nesse sentido, o resultado de suas ações reflete as condições competitivas do país (GADELHA, 2001, p. 155). Portanto, ao fomentar as atividades inovativas dos agentes privados, 
estimulando-os a competir por mercados internacionais com empresas que atuam na fronteira tecnológica, o Estado está atuando na transformação industrial e, com isso, a política industrial funciona como elemento de promoção do desenvolvimento econômico.

Ao se reconhecer a importância do desempenho inovativo de um país sobre o seu nível de desenvolvimento, é possível não apenas analisar as implicações das estratégias competitivas das empresas no âmbito microeconômico, mas também verificar os importantes feedbacks entre os níveis micro e macroeconômicos. Para Possas (1996, p. 73), ao formular e executar estratégias competitivas, a firma procura se diferenciar em relação aos concorrentes com o objetivo de obter lucros extraordinários e vantagens em seu ambiente competitivo, o qual influencia e sofre influência de outros fatores, como o sistema institucional e as condiçôes de infraestrutura. Assim, para que as políticas industrial e de inovação alcancem os objetivos desejados, é necessário considerar os fatores sistêmicos da inovação, isto é, as condições do ambiente competitivo, do sistema econômico e institucional e das infraestruturas essenciais para a obtenção de um ambiente econômico que favoreça o processo de criação de assimetrias competitivas entre os agentes, por meio da criação e ocupação de novos espaços econômicos em busca de lucros supranormais e vantagens competitivas. Este argumento reforça as conclusões de Cimoli et al. (2009) de que o desenvolvimento econômico não depende apenas de políticas que viabilizem os esforços para a promoção do catch up tecnológico, mas também de fortes elos entre os níveis micro e macroeconômicos da inovação. Fatores que promovem o desenvolvimento industrial e econômico, no nível macro, estão ligados diretamente a elementos no nível micro, especificamente no nível da empresa, como a dinâmica de aprendizado dos agentes e o desenvolvimento de capacitações tecnológicas.

Em Possas (1996, p. 99), os fatores sistêmicos da competitividade são divididos em três níveis:

- fatores que estimulam a criação e consolidação de um ambiente competitivo, baseados tanto no uso de instrumentos regulatórios, incluindo os relativos à defesa da concorrência, quanto na política comercial, com o intuito de estimular a pressão competitiva exercida sobre empresas e mercados;

- fatores promotores de externalidades à atividade industrial, tais como infraestruturas de transporte, energia e comunicação, educação básica, bem como infraestrutura científica e tecnológica;

- fatores político-institucionais, abrangendo as políticas macroeconômicas (cambial, fiscal, monetária e creditícia, comercial) e as políticas de fomento 
e promoção (incentivos à ciência e tecnologia - C\&T, às atividades de pesquisa e desenvolvimento - $\mathrm{P} \& \mathrm{D}$, bem como à modernização, via poder de compra do governo).

A justificativa para essa visão sistêmica da política industrial, em acordo com os estudos sobre "sistemas nacionais de inovação", deve-se, segundo o autor, ao atual contexto em que a concorrência se dá basicamente em nível global, entre grandes empresas oligopolistas que atuam na fronteira tecnológica com inovaçôes science based. Uma das funções do sistema nacional de inovação na promoção de competitividade é diluir os riscos dos investimentos em P\&D, estimulando o compartilhamento do esforço científico e tecnológico entre instituiçôes públicas e empresas privadas. Neste contexto, os fatores sistêmicos da competitividade tornam-se elementos-chave para a formulação de uma política industrial, pelo impacto que os fatores sistêmicos têm sobre as decisóes estratégias das firmas.

Partindo-se do argumento desenvolvido por Nelson (1992, p. 348) de que "as capacitaçôes tecnológicas das firmas de uma nação são o fator chave de seu desempenho competitivo, acreditando-se que estas capacitações são, em certo sentido, nacionais, e podem ser construídas por ações nacionais”, é possível defender a ideia de que a atuação da política industrial no aprofundamento da infraestrutura de C\&T é capaz de nortear o desempenho inovativo das empresas nacionais (ainda que os esforços inovativos precisem ser realizados pelas próprias firmas, isto é, que elas sejam os principais protagonistas do processo) por meio do desenvolvimento de tecnologias e práticas necessárias para competir e permanecer ou assumir a liderança em seus mercados.

Na concepção de Nelson (1992, p. 358), as empresas líderes do sistema nacional de inovação são aquelas que possuem mais habilidades para competir. Tais habilidades provêm da sua exposição à forte competição por parcelas seja do mercado nacional ou internacional. Para o autor, enquanto em países com grande contingente populacional e, consequentemente, maior mercado consumidor a força das empresas é caracterizada pela sua capacidade de enfrentar as rivais no mercado doméstico (como é o caso nos EUA e, podemos acrescentar, no Brasil), em países menores (tais como Suécia e Canadá), as empresas frequentemente competem por parcelas do mercado internacional, sobretudo via exportaçôes.

O fato de que as empresas estejam à frente do sistema nacional de inovação em economias desenvolvidas não significa que seu surgimento é espontâneo. Ao contrário, a liderança de Alemanha e EUA em indústrias de alta tecnologia deve-se, em grande medida, ao sistema universitário que direcionou esforços de formação e qualificação para atender às demandas da indústria (NELSON, 1992, p. 359). 
A existência de mão de obra qualificada (e outros insumos do processo inovativo) por si só não é suficiente para apoiar um ambiente competitivo caracterizado por empresas nacionais líderes, mas deve haver compatibilidade entre a demanda de recursos inovativos por parte das empresas e sua oferta. Enquanto a sinergia entre oferta e demanda por recursos inovativos é o que marca o sistema nacional de inovação dos países que estão na fronteira tecnológica, o sistema nacional de inovação brasileiro parece ser caracterizado por um descasamento entre estes elementos. Indicamos como hipótese mais provável que este descasamento reflete um baixo esforço inovativo na indústria brasileira, que se manifesta em baixa demanda por recursos inovativos. Por sua vez, este baixo esforço tende a alargar o hiato tecnológico entre o Brasil e as economias tecnologicamente dinâmicas e a enfraquecer a competitividade internacional da indústria.

\section{Políticas de incentivo à inovação e recursos inovativos existentes no Brasil}

Muitos estudos sobre o desenvolvimento de capacitações tecnológicas no Brasil têm discutido o lado da oferta de mão de obra especializada e o desenvolvimento de um arcabouço institucional para fomentar as atividades de pesquisa e desenvolvimento (AVELLAR, 2010; CASSIOLATO; LASTRES, 1998; ARRUDA et al., 2006; RAPINI, 2007). No entanto, a compreensão adequada dos motivos do baixo dinamismo tecnológico na estrutura produtiva brasileira requer que se avalie não apenas a oferta, mas também a demanda por recursos voltados ao esforço tecnológico. Esta demanda reflete a necessidade dos agentes privados de desenvolver capacitações tecnológicas, buscando reforçar posições competitivas ou criar novos espaços de concorrência.

A literatura aponta uma correlação positiva entre criação de capacitações tecnológicas e competitividade (FIGUEIREDO, 2004; CASSIOLATO; LASTRES, 2005; CRUZ; PACHECO, 2004). No entanto, a maioria das empresas que atuam em economias emergentes não conseguiu alcançar melhores posições competitivas no mercado mundial a partir do desenvolvimento de capacitações para inovar. Para explicar esse fato, Figueiredo (2004) indica que uma característica tecnológica destas empresas é que elas normalmente iniciam suas atividades a partir do uso de tecnologias desenvolvidas em outros países, não dispondo sequer de capacidades tecnológicas básicas. É necessário um longo processo de aprendizado tecnológico para que elas possam se aproximar da fronteira tecnológica nos setores em que atuam. 
As deficiências da base produtiva brasileira em termos de capacitação tecnológica podem ser constatadas a partir de alguns indicadores de inovação, como o gasto setorial em atividades de $\mathrm{P} \& \mathrm{D}$ e outras atividades inovativas como proporção do faturamento das empresas nos setores selecionados. Segundo Cruz e Pacheco (2004), a política de incentivo à inovação foi bem-sucedida na criação de agências nacionais de fomento científico, como a formação de recursos humanos e a pesquisa acadêmica - tendo a Capes e o CNPq como exemplos virtuosos. Com isso, o Brasil aparece no mapa da ciência mundial, a partir dos dados obtidos do Science Citation Index, registrando aumento significativo do número de publicaçôes, saindo de 2 mil publicaçōes por ano, em média, na década de 1980, para cerca de 7 mil em 1998. De acordo com os dados do Ministério da C,T\&I e Capes, o Brasil respondia por $1,15 \%$ dos artigos publicados nos periódicos científicos indexados pela Thomson / Institute for Scientific Information (ISI), em 1998, enquanto sua participação no registro de patentes concedidos no escritório de patentes dos EUA era praticamente nula $(0,05 \%)$. Após dez anos, este quadro sofreu poucas alterações: ainda que a participação do Brasil em artigos indexados pela Thomson/ISI tenha evoluído para 2,63\%, no total de patentes concedidas pelo USPTO permanece inexpressiva $(0,06 \%)$.

A comparação entre Brasil e Coreia do Sul, em relação ao número de patentes concedidas pelo USPTO ao longo de quatro décadas, indica o baixo desempenho inovativo brasileiro (Gráfico 1).

GRÁFICO 1

Participação no total de patentes concedidas pelo USPTO Brasil, Coreia do Sul e China 1964-2013

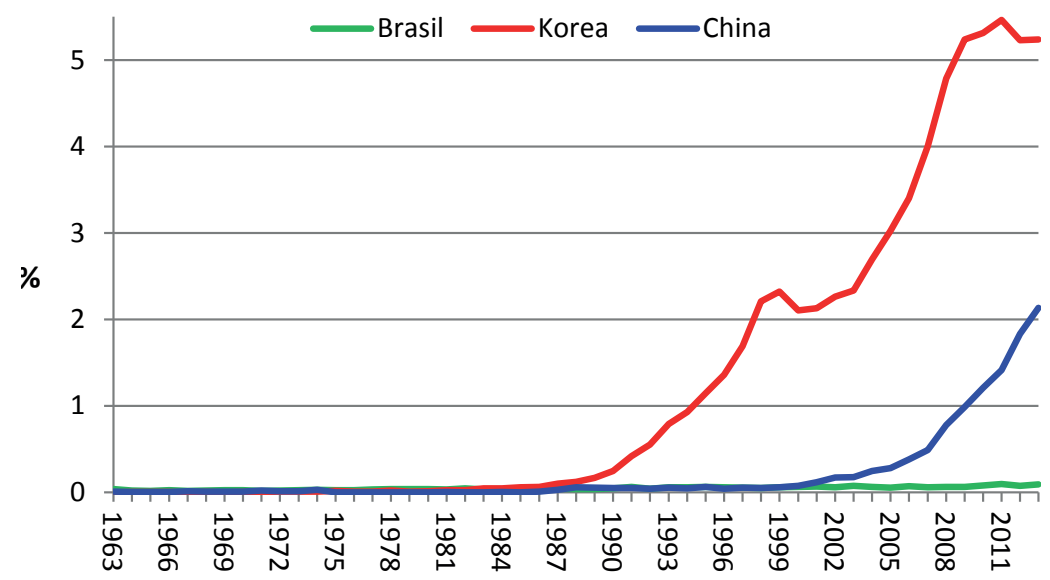

Fonte: U.S. Patent and Trademark Office (USPTO), 2014. 
Enquanto a participação do Brasil no total de patentes concedidas pelo USPTO permanece inexpressiva (próxima a zero) de 1963 a 2011, o crescimento da participação da Coreia do Sul e da China, sobretudo após a segunda metade da década de 1980, é reflexo do alto dinamismo inovativo destes países. Para Cruz e Pacheco (2004), há correlação positiva entre patentes registradas nos EUA e o gasto em P\&D realizado pelas empresas no Brasil e na Coreia do Sul. Na comparação entre os dois países, no início dos anos 1980, ambos registravam menos que uma dezena de patentes nos EUA. Desta data até o presente, o registro de patentes coreanas nos EUA tem crescido exponencialmente, acompanhado pelo investimento empresarial em $\mathrm{P} \& \mathrm{D}$, enquanto no Brasil estes dois indicadores permaneceram estagnados ao longo dos anos.

Assim, apesar de aparecer no mapa da ciência mundial, o Brasil não aparece no mapa da tecnologia mundial. Como as patentes são produtos típicos do ambiente empresarial e não tanto do ambiente acadêmico, esta baixa presença brasileira no panorama tecnológico mundial reflete a concentração de pesquisadores, com nível de doutorado, nas universidades. Segundo dados do Ministério da Ciência e Tecnologia, em 2000, o Brasil empregava aproximadamente 29 mil doutores, divididos em quatro setores institucionais (governo, empresarial, ensino superior, privado sem fins lucrativos). Entre 2000 e 2010, observa-se um crescimento de 186\% no número de doutores empregados, mas a participação destes profissionais no setor empresarial caiu de 4,78\% para 1,73\%, nesse mesmo período, mantendo a concentração dos doutores no ensino superior em torno de $90 \%$. A fraca presença destes profissionais no setor empresarial revela o viés "ofertista" das políticas de C\&T no Brasil, as quais foram capazes de fomentar o desenvolvimento científico do país, porém com fraca interface com o ambiente empresarial, acarretando a subutilização de recursos científicos para a promoção de melhor desempenho tecnológico e competitivo.

Ainda que em países como EUA, Alemanha e Japão as políticas de inovação "do lado da oferta" tenham sido adotadas para o desenvolvimento de infraestrutura de pesquisa, como a criação de agências nacionais de inovação, seus resultados são claramente distintos quando comparados com os do Brasil. A distinção deve-se ao fato de que, na maioria do mundo desenvolvido e em parte das economias em desenvolvimento (essencialmente as asiáticas), o sistema empresarial assumiu a liderança no desenvolvimento tecnológico, ainda que com o fundamental apoio estatal, para promover um esforço deliberado de competitividade internacional. Portanto, não se trata de substituir políticas de oferta por políticas de demanda, mas de construir um sistema - atuante em ambos os lados - capaz de fomentar a competitividade nacional. 
Mesmo que a orientação da política de C\&T tenha mudado de direção nas duas últimas décadas, os resultados alcançados com as políticas implementadas até o momento não foram capazes de reduzir o hiato tecnológico entre o Brasil e os países que estão na fronteira tecnológica, como procuraremos mostrar na próxima seção. Uma das diretrizes de uma política industrial moderna, que busque a inovação e a competitividade, deve ser, a partir um diagnóstico da distância das firmas em relação a seus concorrentes nos países tecnologicamente mais dinâmicos, fomentar as condições do ambiente competitivo que induzam as empresas a envidarem maiores esforços de inovação.

\section{Mensurando o hiato tecnológico brasileiro: uma primeira aproximação}

Como uma tentativa exploratória de mensuração da distância entre atividades tecnológicas realizadas no Brasil e nos países desenvolvidos, apresentamos um conjunto de indicadores a seguir. O pressuposto deste exercício comparativo é que a densidade de determinada atividade tecnológica (medida pelo porcentual de empresas que a praticam) reflete o esforço inovativo e este, por sua vez - conforme discutido nas seçóes 2 e 3 - é um fator-chave de competitividade. Para tanto, foram selecionados seis indicadores de inovação em 13 setores da atividade industrial no Brasil e em nove países europeus: Bélgica, Dinamarca, Alemanha, Espanha, França, Itália, Holanda, Suécia e Noruega. Os indicadores foram construídos com dados extraídos da Community Innovation Survey para 2010 e da Pesquisa da Inovação Tecnológica (Pintec/IBGE) para 2011. ${ }^{2}$ Os indicadores são definidos a seguir, com base no Manual da Pintec (IBGE, 2011) e no Manual Frascati OECD (2002). Para este último, a P\&D é apenas uma etapa do processo de inovação que inclui "o trabalho criativo levado a cabo de forma sistemática para aumentar os campos de conhecimentos [...] e a utilização desses conhecimentos para criar novas aplicações" (OECD, 2002, cap. 2, p. 43). Nessa perspectiva, a inovação tecnológica engloba tanto a P\&D formal, realizada nos laboratórios de P\&D, como a P\&D informal ou ocasional, produzida em outras unidades e nas diferentes atividades. A conceituação dos indicadores de inovação utilizados nesta pesquisa é apresentada a seguir.

2 A CIS é um survey aplicado de forma voluntária às empresas dos países da Comunidade Europeia. A Pintec é um survey compatível aplicado às empresas brasileiras. O caráter voluntário da CIS provoca ausência de informaçôes em alguns países em certos anos e setores. Por isso, os setores e países foram selecionados conforme a disponibilidade que os tornasse comparáveis. Consideraçōes de tamanho e estrutura produtiva também nos levaram a excluir países muito pequenos, como Luxemburgo, Chipre ou Malta. 
- Empresas que realizaram atividades internas de P\&D em relação ao total de empresas em cada setor selecionado ( $\& \& D$ interno): compreende o trabalho criativo, com o objetivo de aumentar o conhecimento e o uso desses conhecimentos para desenvolver novas aplicaçôes, tais como produtos ou processos novos ou substancialmente aprimorados. $\mathrm{O}$ design, a construção e o teste de protótipos e de instalações-piloto constituem, muitas vezes, uma das fases mais importantes das atividades de P\&D. Nessas atividades, está incluído também o desenvolvimento de software, desde que envolva avanço tecnológico ou científico.

- Empresas que realizaram atividades externas de P\&D em relação ao total de empresas em cada setor selecionado ( $\& \& D$ externo): fruto de atividades de P\&D realizadas por outras organizações (empresas ou instituições tecnológicas) e adquirido pela empresa.Empresas que realizaram atividades relacionadas à introdução de produtos novos ou melhorados no mercado, em relação ao total de empresas em cada setor selecionado. Tais atividades consistem em: pesquisas e testes de mercado; adaptação do produto a diferentes mercados; e propaganda (esforços para introdução de inovações).

- Empresas que inovaram em produto e/ou processo em relação ao total de empresas em cada setor selecionado (inovação de produto e processo): uma inovação de produto ou processo consiste na introdução de um produto (bem ou serviço) ou processo novo ou substancialmente aprimorado (IBGE, 2011, p. 5, 8).

A seguir, são apresentados dois indicadores de dispêndio com atividades inovativas. Total de gastos relacionados apenas às atividades de pesquisa e desenvolvimento, incluindo P\&D interna e P\&D externa, em relação ao faturamento líquido dos setores selecionados (Gastos com P\&D).

Total dos gastos relacionados às atividades de inovação ( $P \& D$ interno; $P \& D$ externo; aquisição de conhecimento externo; aquisição de máquinas, equipamentos e software; treinamento) em relação ao faturamento líquido dos setores selecionados (gastos com inovação).Os 13 setores investigados foram agrupados em quatro categorias, de acordo com o critério de intensidade tecnológica proposto pela OECD, na seguinte forma: alta intensidade tecnológica (farmacêutico; equipamentos de informática e produtos eletrônicos e ópticos; outros equipamentos de transporte3); média alta intensidade tecnológica (químico e petroquímico; veículos automotores,

3 Esta atividade inclui os seguintes setores: aeronáutico e aeroespacial; produção de equipamentos para ferrovias; construção e reparação naval. Apenas o setor aeronáutico pode ser classificado como de alta intensidade tecnológica, sendo os outros dois classificados como, respectivamente, atividades de média alta e média baixa tecnologias. 
reboques e carrocerias; máquinas e aparelhos elétricos; máquinas e equipamentos); média baixa intensidade tecnológica (coque e refino de petróleo; plástico e borracha; minerais não-metálicos; metalurgia e siderurgia); e baixa intensidade tecnológica (têxtil; papel e celulose). A forma de apresentação dos resultados segue a proposta de Zucoloto e Toneto (2005), procurando comparar os indicadores obtidos para o Brasil com o valor dos indicadores dos países europeus, apresentados em três níveis de análise (médio, máximo e mínimo).

Em relação aos setores de alta intensidade tecnológica, ainda que 30\% das empresas dos setores farmacêutico e de equipamentos de informática tenham declarado que realizam atividades de P\&D interna (Tabela 1), os gastos em P\&D das empresas nestes dois setores, em relação ao faturamento líquido, não alcançou 3\% (Tabela 2), sendo que a média dos países europeus selecionados, para este indicador, é de 8,1\%.

No caso do setor outros equipamentos de transporte, no qual está incluída a produção de aviōes, considerada uma das atividades tecnologicamente mais dinâmicas do Brasil, 4,6\% das empresas do setor declararam que realizam atividades de P\&D interna, percentual consideravelmente inferior à média dos demais países estudados $(41,4 \%)$. Evidência semelhante é encontrada quando se analisar o indicador gastos em P\&D em relação ao faturamento (Tabela 2). Enquanto o setor no Brasil destina $2 \%$ do faturamento com atividades relacionadas à $\mathrm{P} \& \mathrm{D}$ interna, o conjunto dos países europeus gasta, em média, $4,4 \%$ do faturamento com tais atividades.

O baixo gasto em $P \& D$ e atividades inovativas no setor farmacêutico brasileiro $(3,8 \%)$, muito inferior aos da Bélgica e Dinamarca, países em que este indicador encontra-se acima de 30\% (Tabela 2), se reflete na baixa taxa de introdução de inovaçôes de produto e processo por parte das empresas brasileiras. Enquanto $20 \%$ das empresas do setor farmacêutico brasileiro declararam ter introduzido inovações de produto e processo no mercado (Tabela 1), a média dos países europeus analisados, neste mesmo setor, foi de $33,7 \%$. No caso do setor de equipamentos de informática e produtos eletrônicos, a disparidade dos indicadores entre Brasil e o conjunto de países europeus é ainda maior.

Em relação aos setores de média-alta intensidade tecnológica, a comparação entre o Brasil e os países europeus selecionados revela a existência de divergências tecnológicas importantes para a maioria dos indicadores analisados. No caso das empresas brasileiras, com base nos dados da Pintec 2011, o percentual médio de empresas que realizam P\&D interna é de 16,6\%. Por outro lado, ao considerarmos o conjunto dos países europeus selecionados, cerca de $48,7 \%$ das empresas dedicam-se às atividades de $\mathrm{P} \& \mathrm{D}$ interna, ainda que não haja grande divergência entre o Brasil e 


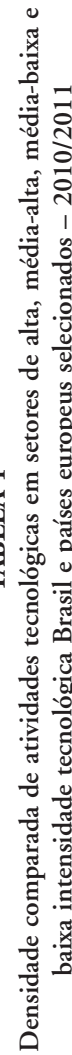




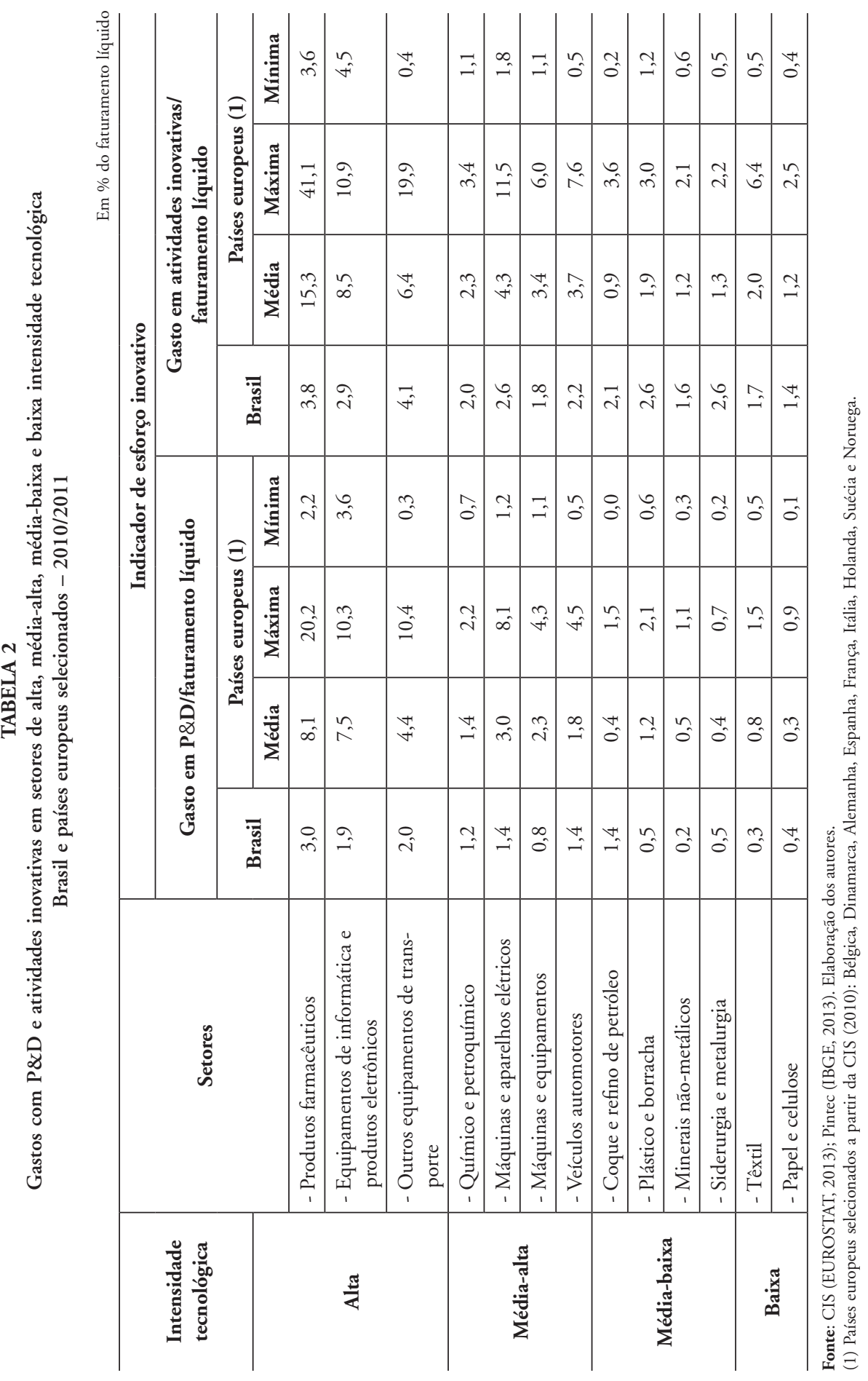


estes países em relação à introdução de inovações no mercado. Para o conjunto dos três setores incluídos nesta categoria, a média brasileira das empresas que declararam ter introduzido inovaçóes de processo ou produto no mercado é $23 \%$, enquanto para os países europeus este indicador foi de aproximadamente $27 \%$.

Os indicadores de gasto com P\&D e com o total de atividades inovativas mostra, por outro lado, um baixo esforço das empresas brasileiras em todos os setores investigados, sobretudo os de alta e média-alta tecnologias. $\mathrm{O}$ único setor em que o Brasil apresenta desempenho inovativo superior à fronteira tecnológica europeia ${ }^{4}$ é o de siderurgia e metalurgia, classificado no grupo de atividades de média-baixa tecnologia. O setor de siderurgia no Brasil realizou gastos em atividades inovativas, como proporção do faturamento líquido, 18,6\% superiores àqueles realizados pela Suécia (Tabela 3). No entanto, há algumas especificidades neste indicador que permitem explicar o bom desempenho brasileiro. Como, para os surveys de inovação utilizados neste trabalho - Pintec e CIS -, os esforços de modernização produtiva podem ser considerados inovação de processo, é possível afirmar que o alto desempenho do Brasil neste indicador não reflete o seu esforço de inovação, mas sim esforço de modernização, traduzido em aquisição de máquinas e equipamentos mais modernos, o que pode, no máximo, ser interpretado como esforço para aumento de produtividade e não esforço inovativo em sentido estrito. Este argumento é corroborado pela análise do indicador gasto em P\&D como proporção do faturamento líquido, na medida em que este indicador considera apenas os gastos associados às atividades de $\mathrm{P} \& \mathrm{D}$, incluindo a aquisição de máquinas e equipamentos; ele não apresenta o problema observado com o indicador anterior. Considerando este indicador, é possível verificar a presença de um hiato tecnológico - 29,3\% (Tabela 3) - entre Brasil e o país europeu mais bem posicionado (Bélgica).

Em relação aos demais setores de média-baixa intensidade tecnológica, observa-se a existência de níveis muito desiguais de desempenho inovativo entre Brasil e os países europeus selecionados, com destaque para o setor de plástico e borracha (Tabela 3). Existe um grande hiato tecnológico neste setor, tanto em termos do número de empresas que realizaram inovaçóes de produto e processo em relação ao total de empresas consideradas (hiato tecnológico $=66,1 \%$ ), quanto em termos do esforço inovativo, medido por meio do gasto com P\&D em relação ao faturamento líquido (hiato tecnológico 79,6\%). O fraco desempenho inovativo do setor de plástico e borracha revela que o baixo dinamismo inovativo brasileiro não se resume

4 O termo "fronteira tecnológica europeia" refere-se ao país europeu mais bem posicionado, entre as economias europeias selecionadas, em relação ao desempenho dos indicadores de inovação desenvolvidos neste artigo. 
apenas às atividades de alto conteúdo tecnológico, incluindo também as atividades mais tradicionais, em que o país possui acúmulo de experiência. Tal situação também caracteriza a produção de coque e refino de petróleo, bem como a produção de minerais não-metálicos. Estes setores são particularmente relevantes por serem atividades em que o país possui importante dotação de recursos minerais. No setor de coque e refino de petróleo, 9,6\% das empresas no Brasil declararam que realizam P\&D interna (Tabela 1). Ao analisarmos estes mesmos indicadores para os países europeus selecionados, verifica-se que a média das empresas do setor que realizam atividades de P\&D interno é de 43,8\% (Tabela 1). Ainda que os gastos das empresas com P\&D no Brasil (Tabela 2) sejam bem elevados $(1,4 \%)$ em relação à média dos países europeus $(0,4 \%)$, isso não gera uma vantagem para o Brasil na introdução de inovaçôes de produto e processo no mercado. Embora 13\% das empresas do setor de coque e refino de petróleo brasileiro tenham declarado ter introduzido inovações no mercado, a média dos países europeus está em 21\% (Tabela 1).

No caso dos setores de baixa tecnologia investigados, há uma clara distância entre o Brasil e os países europeus quando se analise o indicador percentual de empresas engajadas com P\&D interno. No setor têxtil, apenas 4,3\% das empresas realizam atividades de P\&D interna (Tabela 1); por outro lado, este percentual é, em média, de $35 \%$ nos países europeus. Situação semelhante é observada no setor de produção de papel e celulose (7,5\% no Brasil e 27,2\% média europeia). No entanto, em relação à introdução de inovações de produto e processo no mercado, não são verificadas grandes disparidades entre o desempenho inovativo do Brasil e o desempenho médio europeu em ambos os setores. No entanto, a comparação do Brasil com a média europeia não permite verificar o forte atraso tecnológico do país. Na Tabela 3 é possível verificar a distância entre o Brasil e os países com melhor posicionamento dentro da Europa em cada setor. No setor têxtil, o Brasil gasta $81 \%$ a menos que a França em atividades de P\&D como proporção do faturamento líquido e $48 \%$ a menos que a Noruega no setor de papel e celulose. Este baixo esforço tecnológico tem reflexo no fraco desempenho inovativo, medido pela capacidade de introduzir inovações de processo e produto, sendo $52 \%$ inferior à fronteira europeia, no caso da indústria têxtil brasileira, e $37 \%$ inferior no caso da indústria de papel e celulose nacional. A análise do hiato tecnológico nos setores de baixa tecnologia revela que, mesmo em atividades tradicionais, nas quais o Brasil possui acúmulo de experiência na produção e exportação de bens, o baixo dinamismo inovativo é evidente. 


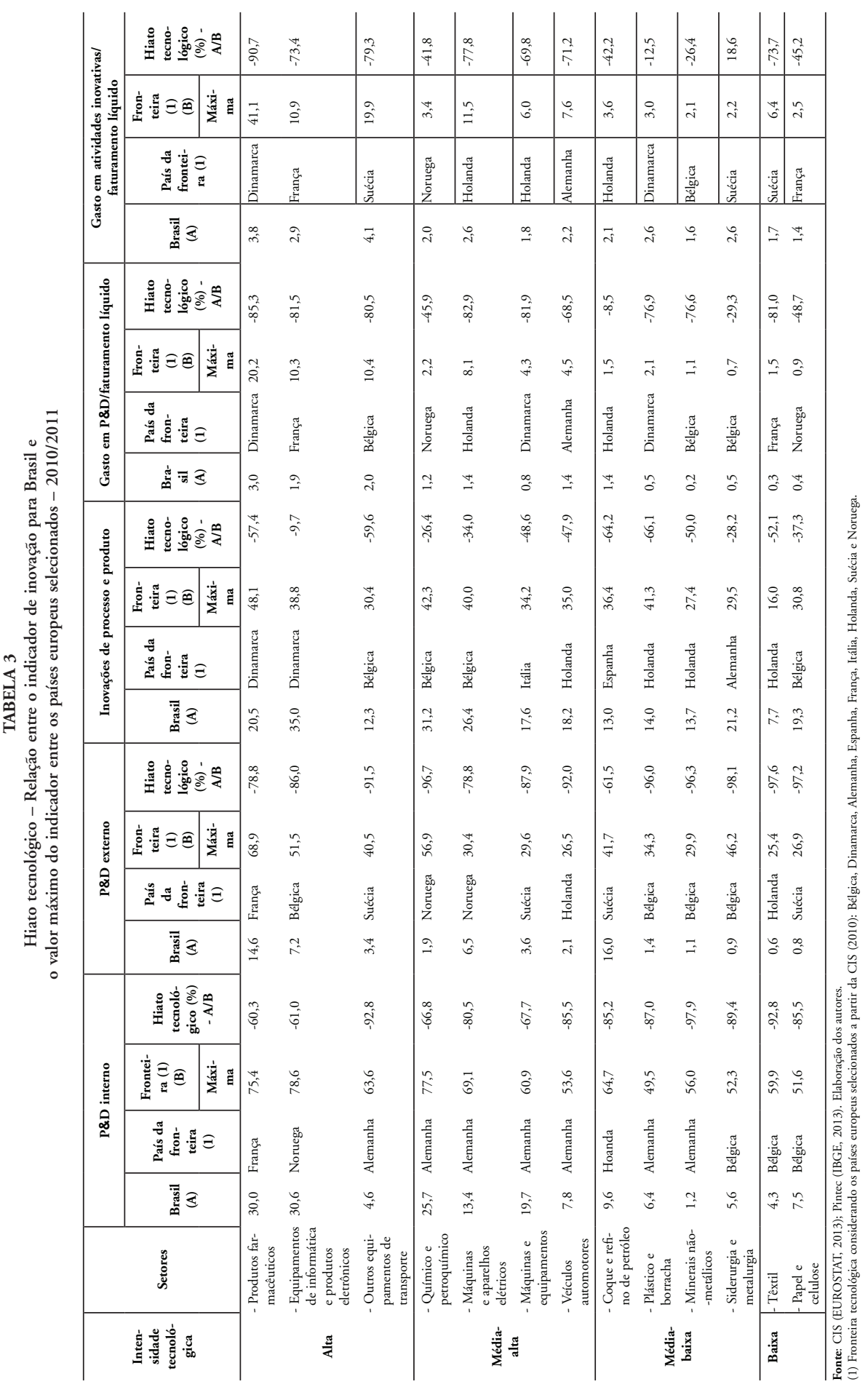




\section{Considerações finais}

Em linha com a teoria evolucionista, o conceito de política industrial adotado neste artigo enfatiza as especificidades e a diversidade da estrutura industrial como elemento decisivo para o desenvolvimento de competitividade da indústria, entendendo-se que a competitividade resulta, em grande medida, da capacidade de suas empresas para reduzir o hiato tecnológico em relação aos concorrentes no mercado internacional. Neste sentido, conforme apontado por muitos autores (GADELHA, 2001; GUERRIERO, 2011; REINER; STARITZ, 2013; REINERT, 2007; CIMOLI et al., 2009), políticas que induzam à realização de atividades inovativas (tanto por incentivos como por sançôes) devem ser atualmente o principal componente da política industrial.

A importância da política de inovação para o desenvolvimento de competências produtivas e tecnológicas na atividade industrial, elevando sua capacidade para competir no mercado internacional, torna-se evidente quando a abordagem lança mão de indicadores de esforço de inovação que traduzem o hiato tecnológico entre o Brasil e um conjunto de países desenvolvidos da Europa. A existência de um grande hiato tecnológico entre o Brasil e os países selecionados, sobretudo em setores de alta e média-alta intensidade tecnológica, é sintomática e provavelmente está relacionada à perda de competitividade das exportaçôes industriais brasileiras. Esta é uma hipótese de trabalho que o presente artigo procurou fundamentar e que será desenvolvida em trabalhos futuros.

Ao observarmos o esforço inovativo do Brasil em comparação a países como Alemanha, Bélgica, França e Dinamarca, a distância tecnológica mostra-se ainda maior. Por exemplo, no caso do setor de veículos automotores, enquanto o Brasil destina $1,4 \%$ do faturamento às atividades de $P \& D$, a Alemanha gasta $4,5 \%$ do faturamento de suas empresas, ou seja, cerca de três vezes mais. Ainda que alguns trabalhos, como o de Nassif et al. (2014), tenham evidenciado mudanças importantes na estrutura produtiva brasileira nos últimos 30 anos, com o aumento da participação dos setores baseados em ciência, conhecimento e engenharia no valor adicionado nacional, este esforço tem se mostrado insuficiente para reduzir o gap tecnológico entre o Brasil e as economias desenvolvidas da Europa.

A fundamentação teórica (seçōes 2 e 3 ) e as evidências empíricas apresentadas (seções 4 e 5) parecem apontar que o foco das políticas de ciência, tecnologia e inovação no provimento de recursos para a inovação, a formação de recursos humanos e a pesquisa acadêmica não tem resultado no desenvolvimento de capacitaçôes 
tecnológicas dos agentes privados. Como consequência, é de se presumir que não deve ter surtido efeito sobre a melhora da posição tecnológica e competitiva do Brasil diante de seus concorrentes no mercado internacional. Dessa forma, uma política de inovação, entendida como a principal orientação da política industrial, deve focalizar prioritariamente os determinantes das decisões empresariais de gastar em atividades inovativas (que determinam a demanda por incentivos públicos). A literatura mostra que a realização de tais atividades e o desenvolvimento de capacitações tecnológicas que a acompanha são eficazes para reforçar posições competitivas e criar novos espaços de concorrência.

\section{Referências bibliográficas}

AGHION, P.; DEWATRIPONT, M.; DU, L.; HARRISON, A.; LEGROS, P. Industrial policy and competition. NBER, maio 2012 (Working paper, n. 18048).

AMENDOLA, G.; DOSI, G.; PAPAGNI, E. The dynamics of industrial competitiveness. Weltwirtschaftliches Archiv, v. 129, n. 3, p. 451-471, set.1993.

ANTIMIANI, A.; CONSTANTINI, V. Trade performances and technology in the enlarged European Union. Journal of Economic Studies, v. 40, n. 3, p. 355-389, 2013.

ARRUDA, M.; VERMULM, R.; HOLLANDA, S. Inovação tecnológica no Brasil: a indústria em busca da competitividade global. São Paulo: Anpei, 2006.

AVELLAR, A. P. Políticas de inovação no Brasil: uma análise com base na PINTEC 2008. Economia \& Tecnologia, ano 6, v. 23, p. 139-149, out./dez. 2010.BELL, M.; PAVITT, $\mathrm{K}$. Technological accumulation and industrial growth: contrasts between developed and developing countries. Industrial and Corporate Change, v. 2, n. 2, p. 157-210, 1993.

The development of technological capabilities. In: HAQUE, I. U. (Ed.). Trade, technology and international competitiveness. Washington: The World Bank, 1995, p. 69-101.

CASSIOLATO, J. E.; LASTRES, M. H. Inovação, globalização e as novas políticas de desenvolvimento industrial e tecnológico. Nota Técnica 21/98. Projeto Globalização e inovação localizada: experiências de sistemas locais no âmbito do Mercosul e proposiçôes de políticas de ciência e tecnologia. Rio de Janeiro, novembro de 1998.

Tecno-globalismo e o papel dos esforços de P\&D\&I de multinacionais no mundo e no Brasil. Brasília: Centro de Gestão e Estudos Estratégicos, outubro 2005. Mimeografado. CHANG, H.-J. Chutando a escada: a estratégia do desenvolvimento em perspectiva histórica. São Paulo: Editora Unesp, 2004. 
CIMOLI, M.; DOSI, G.; STIGLITZ, J. E. The political economy of capabilities accumulation: the past and future of policies for industrial development. In: CIMOLI, M.; DOSI, G.; STIGLITZ, J. E. (Eds.). Industrial policy and development: the political economy of capabilities accumulation. Oxford/New York: Oxford University Press, 2009, p. 1-16.

CRUZ, C. H. B.; PACHECO, C. A. Conhecimento e inovação: desafios do Brasil no século XXI. Campinas, 2004. Disponível em: <www.inovacao.unicamp.br/report/inte-britopache co.html>. Acesso em: 25 nov. 2013.

DEVLIN, R.; MOGUILLANSKY, G. What's new in the new industrial policy in Latin América? In: STIGLITZ, J. E.; LIN, J. (Eds.). The industrial policy revolution I: the role of government beyond ideology. London: International Economic Association, 2013, p. 276-317.

DOSI, G.; SOETE, L. Technology gaps and cost-based adjustment: some explorations on the determinants of international competitiveness. Metroeconomica, v. 35, n. 3, p. 197-222, out. 1983.

Technical change and international trade. In: DOSI, G.; FREEMAN, C.; NELSON, R. R.; SILVERBERG, G.; SOETE, L. (Eds.). Technical change and economic theory. Londres: Pinter Publishers, 1988, p. 401-431.

DOSI, G.; PAVITT, K.; SOETE, L. The economics of technical change and international trade. London: Harvester Wheatsheaf, 1990.

DOSI, G.; GRAZZI, M.; MOSCHELLA, D. Technology and costs in international competitiveness: from countries and sectors to firms. Sant'Anna School, abril 2014 (LEM working paper, n. 2014/10).

ERBER, F. S. O padrão de desenvolvimento industrial e tecnológico e o futuro da indústria brasileira. Revista de Economia Contemporânea, v. 5, n. especial, p. 179-206, 2001.

EUROSTAT. Community Innovation Survey 2010. Luxemburgo: Eurostat, 2013.

FAGERBERG, J. Technology and international differences in growth rates. Journal of Economic Literature, v. 32, n. 3, p. 1147-1175, set. 1994.

FAGERBERG, J.; SRHOLEC, M. National innovation systems, capabilities and economic development. Research Policy, v. 37, n. 9, p. 1417-1435, out. 2008.

FAGERBERG, J.; SRHOLEC, M.; KNELL, M. The competitiveness of nations: why some countries prosper while others fall behind. World Development, v. 35, n. 10, p. 1595-1620, out. 2007.

FAGERBERG, J.; VERSPAGEN, B. One Europe or Several? Causes and consequences of the European stagnation. Workshop The Challenge for Europe in a New Age, Alborg, março 2013. 
FIGUEIREDO, P. N. Aprendizagem tecnológica e aprendizagem industrial em economias emergentes: uma breve contribuição para a implementação e desenho de estudos empíricos e estratégias no Brasil. Revista Brasileira de Inovação, v. 3, n. 2, p. 323-361, jul.-dez. 2004.

GADELHA, C. A. G. Política industrial: uma visão neo-schumpeteriana sistêmica e estrutural. Revista de Economia Política, v. 21, n. 4, p. 149-171, out.-dez. 2001.

GUERRIERO, I. Formulação e avaliação de política industrial e o caso da PDP. 2012. 270 f. Tese (Doutorado em Economia da Indústria e da Tecnologia) - Universidade Federal do Rio de Janeiro, Rio de Janeiro, 2012.

IBGE. Pesquisa de Inovação: instruçôes para o preenchimento do questionário. Rio de Janeiro, 2011.

IBGE. Pesquisa Industrial de Inovação Tecnológica 2011. Rio de Janeiro, 2013.

LALL, S. Technological capabilities and industrialization. World Development, v. 20, n. 2, p. 165-186, fev. 1992.

MAGGI, G. Technology gap and international trade: an evolutionary model. Journal of Evolutionary Economics, v. 3, n. 2, p. 109-126, maio 1993.

MORAIS, J. M. Uma avaliação de programas de apoio financeiro à inovação tecnológica com base nos Fundos Setoriais e na Lei de Inovação. In: NEGRI, J. A.; KOBOTA, L. C. (Orgs.). Políticas de incentivo à inovação tecnológica no Brasil. Brasília: Ipea, 2008, p. 68-105.

NASSIF, A.; FEIJÓ, C.; ARAUJO, E. Structural change and economic development: is Brazil catching up or falling behind? Cambridge Journal of Economics, p. 1-26, 2014.

NELSON, R. R. National Innovation Systems: a retrospective on a study. Industrial and Corporate Change, v. 1, n. 2, p. 347-374, 1992.

NELSON, R. R.; WINTER, S. G. An evolutionary theory of economic change. Cambridge MA: Belknap Press of Harvard University Press, 1982.

O’SUllivan, E.; ANDREONI, A.; LÓPEZ-GÓMEZ, C.; GREGORY, M. What is new in the new industrial policy? A manufacturing systems perspective. Oxford Review of Economic Policy, v. 29, n. 2, p. 432-462, verão 2013.

OECD. Frascati Manual: proposed standard practice for surveys on research and experimental development. Paris: OECD Publications Service, 2002.

Perspectives on global development 2013 - Industrial policy in a changing world.

Paris: OECD Publishing, 2013.

PACHECO, C. A. A criação dos fundos setoriais de ciência e tecnologia. Revista Brasileira de Inovação, v. 6, n. 1, p. 191-223, jan.-jun. 2007. 
POSNER, M. V. International trade and technical change. Oxford Economic Papers, v. 13, n. 3, p. 323-341, out. 1961.

POSSAS, M. L. Competitividade: fatores sistêmicos e política industrial: implicações para o Brasil. In: CASTRO, A. B.; POSSAS, M. L.; PROENÇA, A. (Orgs.). Estratégias empresariais na indústria brasileira: discutindo mudanças. Rio de Janeiro: Forense Universitária, 1996, p. 71-117.

POSSAS, M. S. Concorrência e competitividade: notas sobre estratégia e dinâmica seletiva na economia capitalista. São Paulo: Hucitec, 1999.

RAPINI, M. S. Interação universidade-empresa no Brasil: evidências do Diretório dos Grupos de Pesquisa do CNPq. Estudos Econômicos, v. 37, n. 1, p. 211-233, jan.-mar. 2007.

REINER, C.; STARITZ, C. Private sector development and industrial policy: why, how and for whom?. In: ÖSTERREICHISCHEN FORSCHUNGSSTIFTUNG FÜR INTERNATIONALE ENTWICKLUNG (ÖFSE). Private sector development: einneuer businessplan für entwicklung? Viena: ÖFSE, 2013, p. 53-61.

REINERT, E. S. How rich countries got rich... and why poor countries stay poor. London: Constable, 2007.

RODRIK, D. Industrial development: stylized facts and policies. Harvard University, agosto 2006. Disponível em: <http://www.ksg.harvard.edu/rodrik/> Acesso em: 23 jul. 2014.

SCHUMPETER, J. A. Capitalism, socialism and democracy. New York: Harper \& Row, 1942.

STIGLITZ, J. E.; LIN, J.; MONGA, C. Introduction: the rejuvenation of industrial policy. In: STIGLITZ, J. E.; LIN, J. (Eds.). The industrial policy revolution I: the role of government beyond ideology. London: International Economic Association, 2013, p. 1-15.

TIGRE, P. B. O papel da política tecnológica na promoção das exportações. In: PINHEIRO, A. C.; MARKWALD, R.; PEREIRA, L. V. (Orgs.). O desafio das exportaçôes. Rio de Janeiro: BNDES, 2002, p. 245-282.

WARWICK, K. Beyond industrial policy: emerging issues and new trends. OECD Science, Technology and Industry Policy Papers, n. 2, 2013.

ZUCOLOTO, G. F; TONETO JR., R. Esforço tecnológico da indústria de transformação brasileira: uma comparação com países selecionados. Revista de Economia Contemporânea, v. 9, n. 2, p. 337-365, 2005. 